Article

\title{
Nonlinear Digital Simulation Models of Switched Reluctance Motor Drive
}

\author{
Xing Wang ${ }^{1}$, Ryszard Palka ${ }^{2} \mathbb{C}$ and Marcin Wardach ${ }^{2, *(1)}$ \\ 1 Clean Energy Conversion and Power Generation Research Centre, China University of Mining and \\ Technology, Xuzhou 221116, China; wxstarwx@163.com \\ 2 Department of Power Systems and Electrical Drives, West Pomeranian University of Technology, \\ 70-313 Szczecin, Poland; Ryszard.Palka@zut.edu.pl \\ * Correspondence: marwar@zut.edu.pl
}

Received: 15 November 2020; Accepted: 17 December 2020; Published: 19 December 2020

\begin{abstract}
The paper deals with nonlinear simulation models of a drive consisting of the four-phase $8 / 6$ doubly salient switched reluctance motor (SRM), the four-phase dissymmetric bridge power converter and the closed-cycle rotor speed control strategy carried out by the pulse width modulation (PWM) with variable angle and combined control scheme with the PI algorithm. All presented considerations are based on a MATLAB-SIMULINK platform. The nonlinear mathematical model of the analyzed SRM drive was obtained as a combination of the two dimensional (2D) finite element model (FEM) of the motor and the nonlinear model of the electrical network of the power supply circuit. The main model and its seven sub-modules, such as the controller module, one phase simulation module, rotor position angle transformation module, power system module, phase current operation module, "subsystem" module, and electromagnetic torque of one phase operation module, are described. MATLAB functions store the magnetization curves data of the motor obtained by the 2D FEM electromagnetic field calculations, as well as the data of magnetic co-energy curves of the motor calculated from the magnetization curves. The 2D specimen insert method is adopted in MATLAB functions for operating the flux linkage and the magnetic co-energy at the given phase current and rotor position. The phase current waveforms obtained during simulations match with the tested experimentally phases current waveforms at the same rotor speed and the same load basically. The simulated rotor speed curves also agree with the experimental rotor speed curves. This means that the method of suggested nonlinear simulation models of the analyzed SRM drive is correct, and the model is accurate.
\end{abstract}

Keywords: motor control; switched reluctance motor; MATLAB; simulation

\section{Introduction}

The switched reluctance motor (SRM) drive, described comprehensively in [1], has been developed for mining equipment [2], electric vehicles [3], high speed equipment [4], different generators [5,6], wind generators [7], high speed and high power applications [8,9], flywheel energy storage applications [10], linear transportation [11], automotive applications [12], and so on, due to favorable conditions in the design of the motor and power supply, ease of four quadrants operation, high start torque with low start current, high efficiency within vast rotor speed ranges, high dependability with the independence of magnetic paths for each phase and the independence of circuits in each phase. The performance of switched reluctance motors is better than that of the hysteresis direct torque control of permanent-magnet synchronous motor system [13]. The SRM drive generally requires closed-cycle rotor speed control, where the opening angle and the turn-off angle of the power 
transistors, the chopping limitation of phase current, and the average phase voltage are the rotor speed control parameters.

Digital industrial controllers based on field programable gate array technologies are developed to implement artificial intelligence for industrial control applications of advanced drives [14]. The neural estimators are implemented for control of two-mass system with digital field programable gate array hardware [15]. The electric propulsion systems managed and controlled by a digital electronic control unit are designed for light electric vehicles [16]. A model with an adaptive control system for the flexible joint drive system based on the accommodative sliding neuro-fuzzy speed controller has been presented in [17]. The model of the communication network with time-delay was effectively handled by Smith predictor [18]. The description, modeling and control of discrete event systems for machines control logic project are developed in [19].

As with the developed novel mechatronics system [20-23], it is essential to integrate the double salient reluctance motor and power supply of single polarity when creating simulation models of the SRM drive. It is also important to set up an appropriate control scheme and strategy, together with the regulation algorithm which can be used for comparing and selecting the closed-loop rotor speed control algorithms. Such an approach can improve the control parameters and increase drive efficiency.

Because the magnetic characteristics of the motor parts, especially the iron core, are nonlinear and the power network also has nonlinear characteristics, the analyzed SRM drive system is also nonlinear. Considering the above, the simulation models of the SRM drive system should also take into consideration all nonlinear mathematical dependencies. For the active simulation of the SRM a flexible modeling technique within the SABER environment has been developed [24]. Thanks to this model, comprehensive modeling of a vast range of control policies and proper switching control angles could be performed. The model can reasonably predict the flux-linkage characteristics of the typical two-phase impelled 6/4 SRM drive [25]. An improved active model of a three-phase SRM includes modeling of influence of iron loss on current waveform, transient torque and hysteresis, eddy-current and extra iron losses $[9,26]$. An active modeling strategy of SRMs for synchronous two-phase excitation has been presented in [27]. To carry out a simulation model using MATLAB-SIMULINK software, the flux linkage data required for the model were measured experimentally by expanding the procedure for gauging single phase flux characteristics, and the gauged flux linkage data have been used. Modeling of SRMs using an adaptive neural fuzzy inference system (ANFIS) can be applied to study switched reluctance motor dynamic performance by torque and current models [28]. It has been shown that the reduplicative process is very helpful simulation tool in developing a servo-type four-quadrant SRM drive system [29]. Taking into account the machine nonlinearities the paper, [30] presents the flux linkage new analytical expression of a SRM as a function of the rotor position and current. According to the presented model, it may be concluded that a Fourier series representation can estimate the rotor position dependency on the flux linkage. The paper [31] states that a nonlinear model of SRM is characterized by state variables which are constant in the steady-state. This in turn facilitates the high-speed simulation, control and design of the machine. Nonlinearities of SRM resulting from the magnetic saturation and a non-sinusoidal self-inductance profile, causes complications in deriving this model. The difficulties were conquered by introducing a variable representation which approaches motor variables by the time-varying quotient vector and inner product of a vector of basic functions. In high-performance systems for the real-time control, models based on invertible equation can be very helpful. This expression is useful when the set current is derived of the torque command and denoting the torque-phase current relationship [32]. Paper [33] presents a novel rapid nonlinear simulation method for SRMs. This method uses the relationship among the magnetization curves of the machine estimated based on the curve matching the parameters of the Torrey model.

Many problems connected with the SRM design and its applications (mechanical, acoustic and thermal properties, losses, etc.) were discussed in [34], where additionally some significant comments and recommendations for the SRM power electronics are given. Additionally, in paper [35] a procedure 
similar to the one proposed in this paper for the improvement of the low-speed performance of SRMs is presented.

The main goal of the paper was to develop the nonlinear simulation models of the advanced SRM drive using the MATLAB platform combined with the 2D electromagnetic field FE analysis and SIMULINK software. The nonlinear electrical meshwork model of the 4-phase asymmetric bridge SRM power supply circuit and the closed-cycle rotor speed control strategy have been realized by the variable angle pulse width modulation control scheme together with the PI algorithm. Finally, the simulation solution of phase current waveforms and rotor speed curves were compared with the measured waveforms for a real four-phase $8 / 6$ poles SRM motor.

This developed procedure is similar to the algorithm given in [36], where the multi-objective finite element model (FEM) optimization of a PMSM motor was performed with the help of MATLAB and ANSYS-Maxwell scripting capabilities. This result was used after that in paper [37] for the synthesis of the dead-beat current controller for this motor.

\section{System Components and Mathematical Model}

The analyzed SRM drive prototype consists of a four-phase 8/6 poles SRM and its four-phase asymmetric bridge power supply. The cross-section of the SRM under consideration has been shown in Figure 1. One phase winding of the motor is composed by two coils placed on the opposite stator poles. The motor windings are supplied by the current from the bridge power supply.

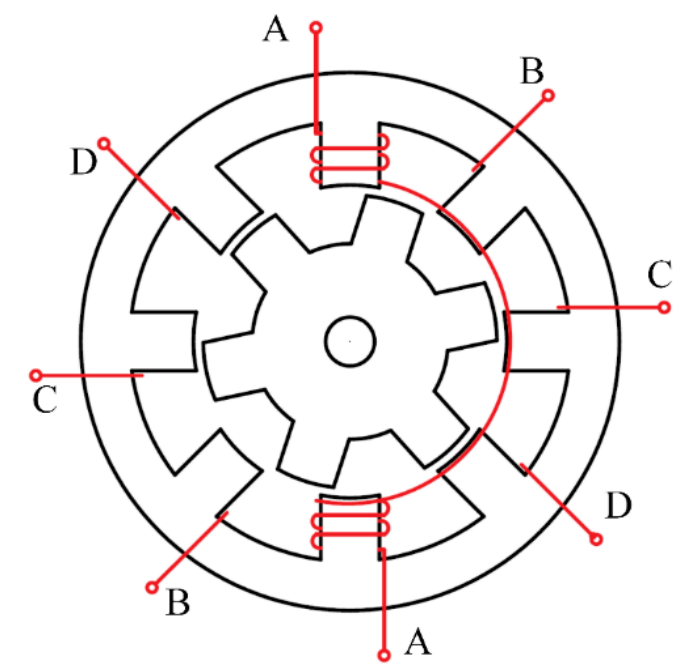

Figure 1. Cross-section of the four-phase $8 / 6$ poles switched reluctance motor (SRM).

The topology of power circuit is shown in Figure 2. It consists of two major switches and two diodes in every phase of the power supply system.

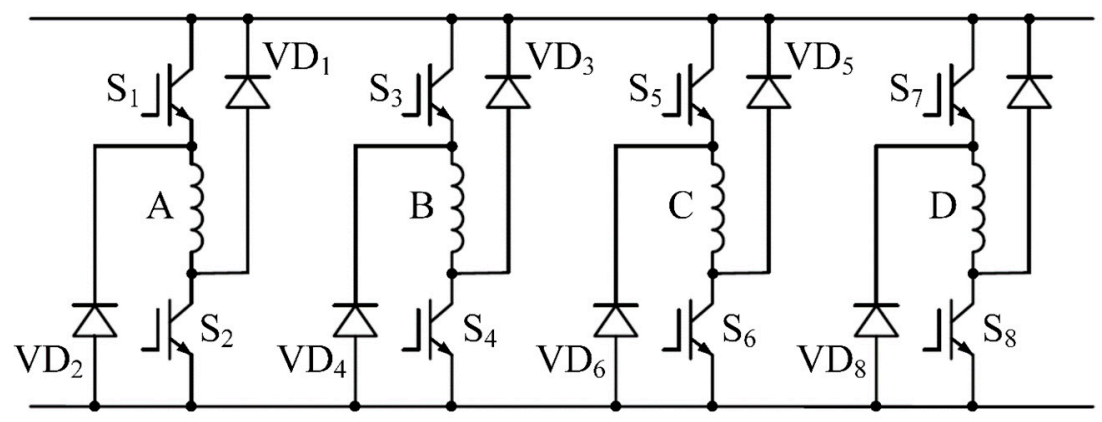

Figure 2. Topology of the power converter main circuit. 
The alterable angle PWM combined control scheme with the PI algorithm is used for the closed-cycle rotor speed drive control. The opening angle of the major switches, $\theta_{1}$, and the turn-off angle of the main switches, $\theta_{2}$, at the two rotor speed values are given in Table 1 , where $\left(\theta_{1}\right.$ and $\theta_{2}=0$ are defined as the rotor position while the axis of the rotor slot is in accordance with that of the stator pole of the conducting phase).

Table 1. $\theta_{1}$ and $\theta_{2}$ at the different rotor speed ranges.

\begin{tabular}{ccc}
\hline $\mathbf{n}(\mathbf{r} / \mathbf{m i n})$ & $\boldsymbol{\theta}_{\mathbf{1}}$ & $\boldsymbol{\theta}_{\mathbf{2}}$ \\
\hline $100 \sim 500$ & $2.5^{\circ}$ & $22.5^{\circ}$ \\
$500 \sim 1000$ & $0^{\circ}$ & $22.5^{\circ}$ \\
\hline
\end{tabular}

The developed mathematical model of this SRM drive is in fact the nonlinear model of the electrical circuit of the power supply system combined with the two 2D FE motor models. Neglecting mutual inductances, it becomes [1]:

$$
\left[\begin{array}{c}
U_{A}\left(\theta_{A}\right) \\
U_{B}\left(\theta_{A}-\theta_{r} / 4\right) \\
U_{C}\left(\theta_{A}-\theta_{r} / 2\right) \\
U_{D}\left(\theta_{A}-3 \theta_{r} / 4\right)
\end{array}\right]=\left[\begin{array}{cccc}
R_{A}+\frac{\partial \psi_{A}}{\partial i_{A}} \cdot D & 0 & 0 & 0 \\
0 & R_{B}+\frac{\partial \psi_{B}}{\partial i_{B}} \cdot D & 0 & 0 \\
0 & 0 & R_{C}+\frac{\partial \psi_{C}}{\partial i_{C}} \cdot D & 0 \\
0 & 0 & 0 & R_{D}+\frac{\partial \psi_{D}}{\partial i_{D}} \cdot D
\end{array}\right]\left[\begin{array}{c}
i_{A} \\
i_{B} \\
i_{C} \\
i_{D}
\end{array}\right]+\omega \cdot\left[\begin{array}{c}
\frac{\partial \psi_{A}}{\partial \theta_{A}} \\
\frac{\partial \psi_{B}}{\partial\left(\theta_{A}-\theta_{r} / 4\right)} \\
\frac{\partial \psi_{C}}{\partial\left(\theta_{A}-\theta_{r} / 2\right)} \\
\frac{\partial \psi_{D}}{\partial\left(\theta_{A}-3 \theta_{r} / 4\right)}
\end{array}\right]
$$

where:

$D i_{k}=d i_{k} / d t,(k=A, B, C, D)$,

$U_{A}, U_{B}, U_{C}, U_{D}$-voltages of phases $A, B, C$ and $D$,

$\theta_{A}$-the rotor position of phase $A$,

$\theta_{r}$-one rotor period,

$R_{A}, R_{B}, R_{C}, R_{D}$-resistances of phases $A, B, C$ and $D$,

$\Psi_{A}, \Psi_{B}, \Psi_{C}, \Psi_{D}$-flux linkages of phases $A, B, C$ and $D$,

$i_{A}, i_{B}, i_{C}, i_{D}$-currents in phases $A, B, C$ and $D$,

$\omega$-the rotor angular velocity,

$t$-the time,

and

$$
\psi_{k}=\frac{N l}{3 S} \sum\left(A_{i} \Delta_{i}-A_{j} \Delta_{j}\right)_{k^{\prime}} k=A, B, C, D,
$$

where:

$N$-each phase turn numbers of winding,

$L$-active length of motor iron core,

$S$-stator pole area at one side,

$\Delta_{i}$ and $\Delta_{j}$-area of the split cell at the right and left side of the stator poles,

$A_{i}$ and $A_{j}$-magnetomotive force vector of the split cell at the right and left side of the stator poles, separately.

The typical equation for the magnetic vector potential (together with the homogeneous boundary conditions) describes the magnetic field distribution within the SRM:

$$
\left\{\begin{array}{c}
\frac{\partial}{\partial x}\left(\gamma \frac{\partial A}{\partial x}\right)+\frac{\partial}{\partial y}\left(\gamma \frac{\partial A}{\partial y}\right)=-J \\
\left.A\right|_{D_{2}, d_{2}}=0
\end{array},\right.
$$

where: 
$\gamma$-the reciprocal of permeability,

$J$-stator phase winding current density,

$\mathrm{D}_{2}$ - outer diameter of stator,

$d_{2}$-diameter of rotor bore,

$A$-magnetic vector potential.

Figure 3 shows the computational cross-section of the analyzed motor.

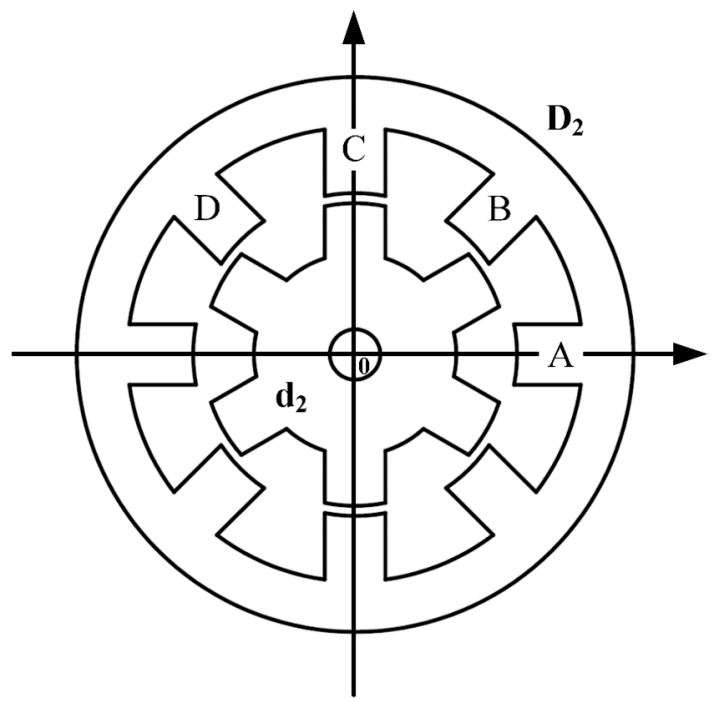

Figure 3. Analyzed cross-section of the motor.

The machine phase voltages can be expressed using equations:

(1) During the supply part of cycle, when the major switches in one phase are open

$$
U_{k}=U_{S}-2 U_{T}, k=A, B, C, D ，
$$

where $U_{S}$ is the DC supply voltage of the power supply, and $U_{T}$ is the on-state voltage drop of the major switch.

(2) During the course of commutation, the major switches in one phase circuit are closed

$$
U_{k}=-U_{S}-2 U_{D}, k=A, B, C, D,
$$

where, $U_{D}$ is the diode on-state voltage drop.

(3) While the power supply does not work, the current in phase is naturally continuous and one phase major switch is turned off,

$$
U_{k}=-U_{T}-U_{D}, k=A, B, C, D,
$$

The system equation of the mechanical motion can be written as $[1,12,35]$ :

$$
\begin{gathered}
T_{e}=J \frac{d \omega}{d t}+H \omega+T_{L}, \\
\frac{d \theta}{d t}=\omega,
\end{gathered}
$$

where $J$ is the sum of inertia moments of the motor and loads, $T_{e}$ is the electromagnetic torque of the motor, $T_{L}$ is the torque of the loads, $H$ is the viscous coefficient of friction, $t$ is the time period and $\theta$ is the rotor position. 


\section{Simulation Models}

The nonlinear simulation model of the SRM drive developed by MATLAB-SIMULINK platform is given in Figure 4. In this model, the turn-on angle of the major switches in the power converter, $\theta_{1}$, is fixed at "Xon", the turn-off angle of the major switches in the power supply system, $\theta_{2}$, is fixed at "Xoff", which is shown for different rotor speeds ranges in Table 1. "Us" is the DC supply voltage of the power supply, " $\theta$ " is the rotor position, " $\omega$ " is the angular speed of the motor, " $n$ " is the set speed, " $n$ " is the practical rotor speed, " $D$ " is the duty ratio of the pulse width modulation signal, " $n$ " is the given rotor speed, " $T e$ " is the total electromagnetic torque of the motor, " $T a$ ", " $T b^{\prime}$, " $T c$ ", and " $T d$ " are the electromagnetic torque in A phase, B phase, C phase, D phase, separately, "TL" is the load, " $J$ " is the sum of all system inertia moments, " $H$ " is the viscous coefficient of friction, " $i a^{\prime \prime}$, " $i b$ ", " $i c$ ", and " $i d$ " are the phase current in A phase, B phase, C phase, D phase, separately. The "PI controller" module is responsible for the closed-cycle rotor speed control. The expanding module of "PI controller" is shown in Figure 5, where, " $K p$ " is the proportion coefficient, " $K_{I}$ " is the integral coefficient, the input "in1" is the difference among the given rotor speed and the real rotor speed, the output "out1" is the duty ratio of the pulse width modulation semaphore, and the "saturation" is used to limit the duty ratio between 0.000 and 1.000 .

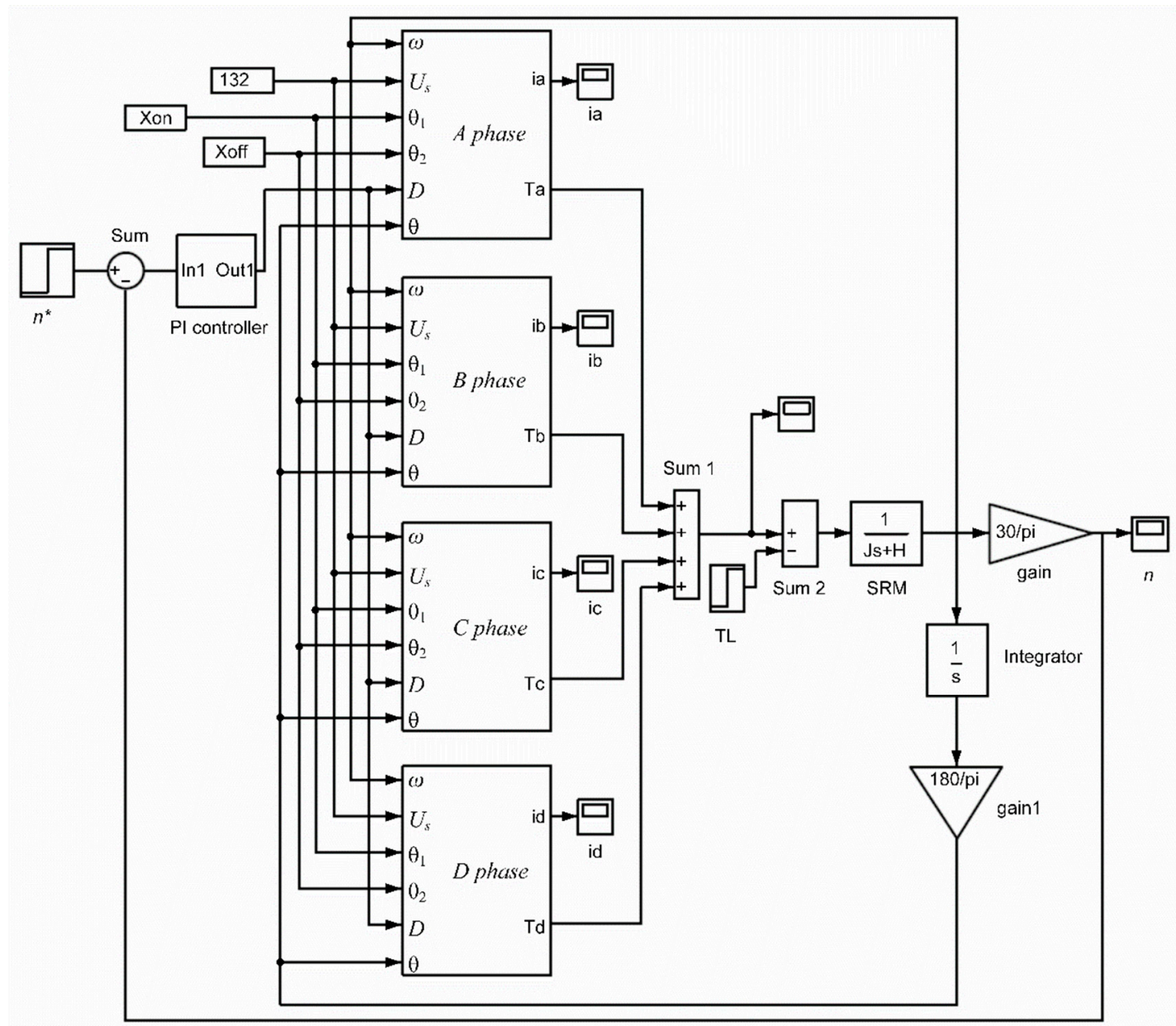

Figure 4. Nonlinear simulation main model of the switched reluctance motor drive. 


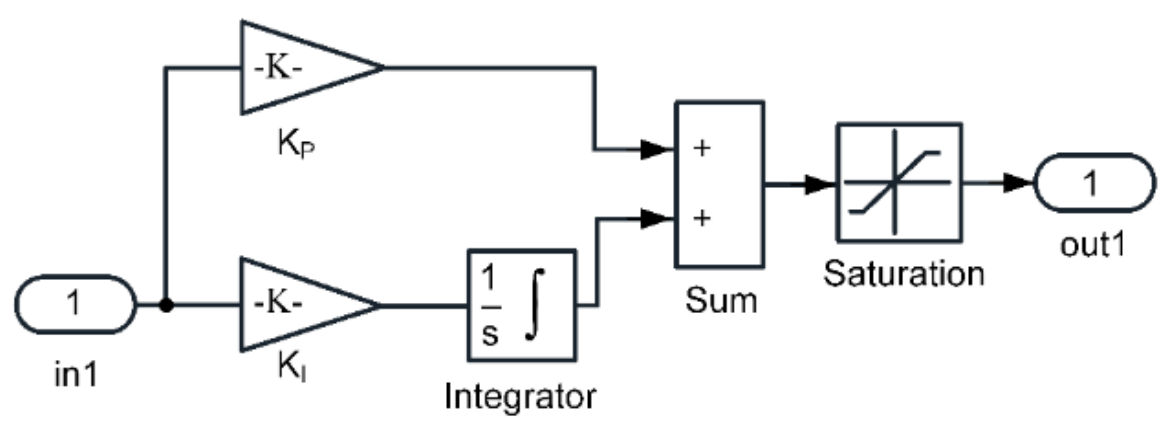

Figure 5. Controller module.

One phase simulation module of the main model is shown in Figure 6. It contains the power system module "converter", the phase current computation module "calculating $i$ ", the one phase electromagnetic torque calculation module "calculating $T$ ", the rotor place angle conversion module " $\theta$ conversion". The phase difference of the analyzed SRM is $15^{\circ}$. The rotor position angle conversion module is used to convert the real rotor position of every phase as the relative rotor position. The expanding rotor position angle conversion module is indicated in Figure 7. The input "ln1" is the absolute rotor place angle, and the output "out1" is the relative rotor position of the certain phase. "Constant" is one rotor period, $\theta_{r}$, such as one rotor period of four-phase $8 / 6$ is $60^{\circ}$. "Constant 1 " is $0^{\circ}$ for $A$ phase, $15^{\circ}$ for $B$ phase, $30^{\circ}$ for $C$ phase, and $45^{\circ}$ for $D$ phase.

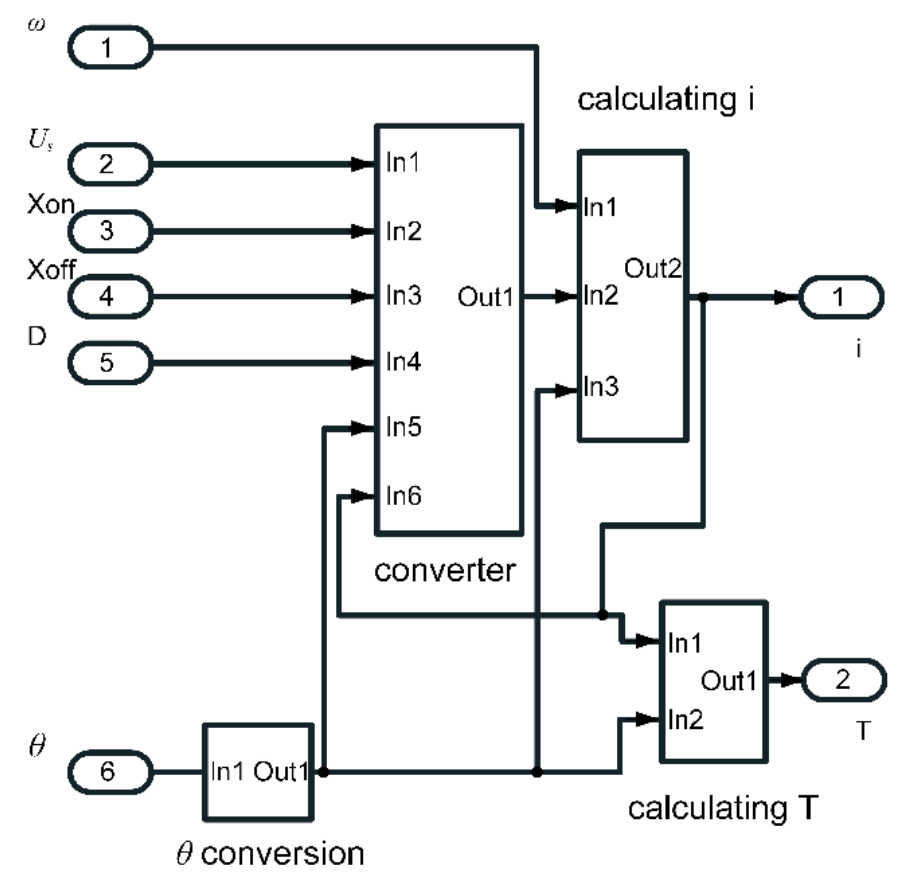

Figure 6. One phase simulation module.

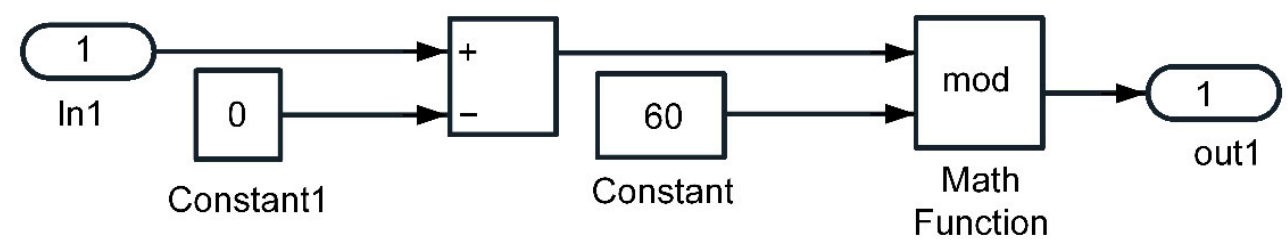

Figure 7. Rotor position conversion module.

Figure 8 presents the module of the expanding power converter, where the import of module "ln1" $\sim$ "ln6", are the DC supply voltages, respectively. This module contains also turn-on and turn-off 
angles of the major switches, a pulse width modulation duty ratio, position angle of the machine rotor, phase currents respectively, and an output "out1", which is the phase voltage " $U_{k}$ ". Proposed "MATLAB Function" is used to calculate the phase voltages, and contains switches "turn-on" and "turn-off" rule. This rule is based on the PWM duty ratio. The "MATLAB Function" includes also opening angle and major switches turn-off angle. While $\theta_{1} \leq \theta \leq \theta_{2}$, if the PWM semaphore is " 1 ", the phase voltage is expressed by Equation (4), if the PWM semaphore is " 0 ", the phase voltage is denoted as Equation (6). While $\theta>\theta_{2}$, the phase voltage is expressed by Equation (5) if the phase current exists, and the phase voltage is zero if the phase current does not exist. While $\theta<\theta_{1}$, the voltage is zero if the phase current does not exist, and the voltage is expressed by Equation (5) if the current in phase exists.

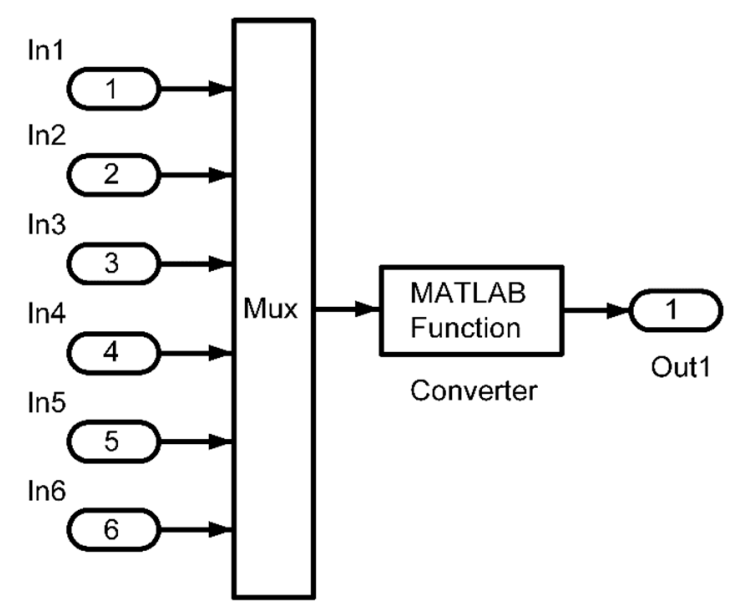

Figure 8. Power converter module.

From Equation (1), we have:

$$
\frac{d i_{k}}{d t}=\frac{U_{k}-R_{k} i_{k}-\frac{\partial \psi_{k}}{\partial \theta} \omega}{\partial \psi_{k} / \partial i_{k}} .
$$

Based on the Equation (9), the simulation model of the phase current calculation module is shown in Figure 9. The import of module, "ln1" $\sim$ "ln3", are the rotor angular velocity, the phase voltage, the converted relative rotor place, respectively, and the export of module "out1" is the instantaneous phase current. "Subsystem" is the module for calculating $\partial \Psi / \partial i$ and $\partial \Psi / \partial \theta$, which are gained by the magnetization curves of the motor.

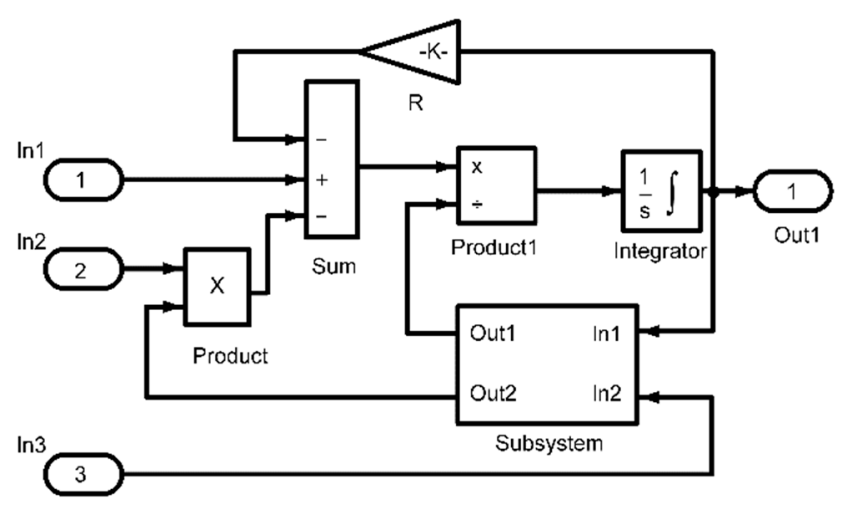

Figure 9. Phase current calculation module. 
Finally, we have:

$$
\left\{\begin{array}{l}
\frac{\partial \psi}{\partial i}=\frac{\psi(i+\Delta i, \theta)-\psi(i, \theta)}{\Delta i} \\
\frac{\partial \psi}{\partial \theta}=\frac{\psi(i, \theta+\Delta \theta)-\psi(i, \theta)}{\Delta \theta}
\end{array},\right.
$$

Based on Equation (10), the expanding "Subsystem" module is shown in Figure 10.

In the module, "in1" is the instantaneous current value, "in2" is the instantaneous converted relative rotor position value, "out1" is $\partial \Psi / \partial i$, and "out2" is $\partial \Psi / \partial \theta$. In the "Subsystem" the current incremental quantity $\Delta i$ is calculated from "Constant1" and "Constant2", but the rotor place incremental quantity $\Delta \theta$ is calculated from "Constant3" and "Constant4". Figure 11 shows magnetization map of analyzed motor, computed by the electromagnetic 2D FEM. These curves are stored in MATLAB Functions by data, such as "MATLAB Fcn1", "MATLAB Fcn2", "MATLAB Fcn3" presented in Figure 10. In order to compute the flux linkage at the given rotor position and phase current, in view of the magnetization curves, the "MATLAB Function" with the 2-D specimen insert method has been adopted.

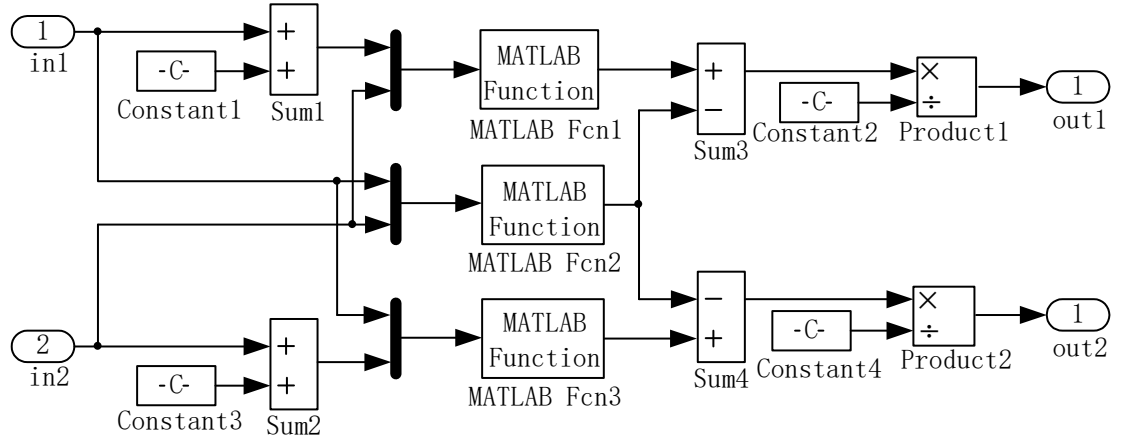

Figure 10. Expanded "Subsystem" module.

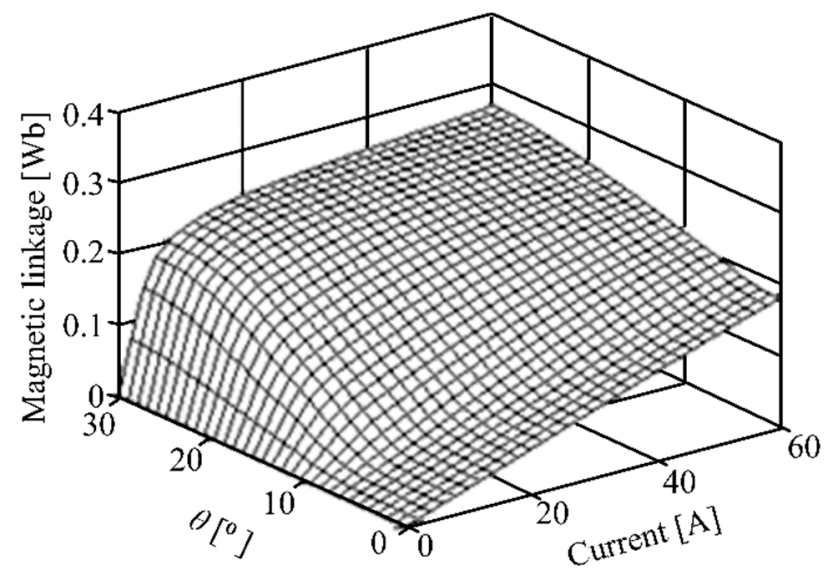

Figure 11. Magnetization map.

According to Equations (9) and (10) and Figures 6-10, the 2D FE model of the electric machine and the nonlinear electrical meshwork model of the power system have been integrated. The magnetic co-energy of the motor can be computed as follows:

$$
W^{\prime}=\int_{0}^{i_{k}} \psi_{k} d i
$$

The magnetic co-energy curves of the motor are calculated by Equation (11) based on the magnetization curves in Figure 11. They are shown in Figure 12. 


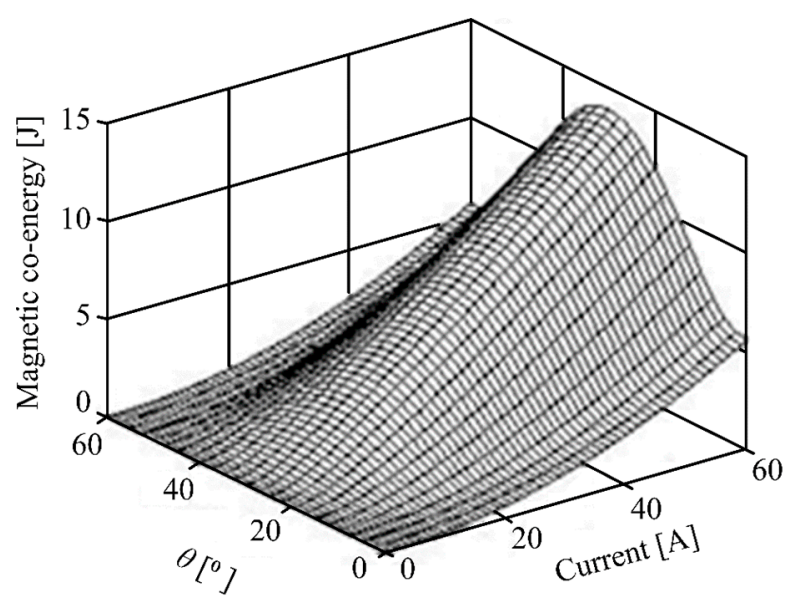

Figure 12. Magnetic co-energy surfaces.

The equation for calculating electromagnetic torque generated by each phase of the double salient reluctance machine can be written as

$$
T_{k}=\left.\frac{\partial W^{\prime}}{\partial \theta}\right|_{i_{k}=\text { const }}=\left.\frac{W^{\prime}(\theta+\Delta \theta)-W^{\prime}(\theta)}{\Delta \theta}\right|_{i_{k}=\text { const }} .
$$

Based on the Equation (12), the simulation model of one phase electromagnetic torque computation module is shown in Figure 13.

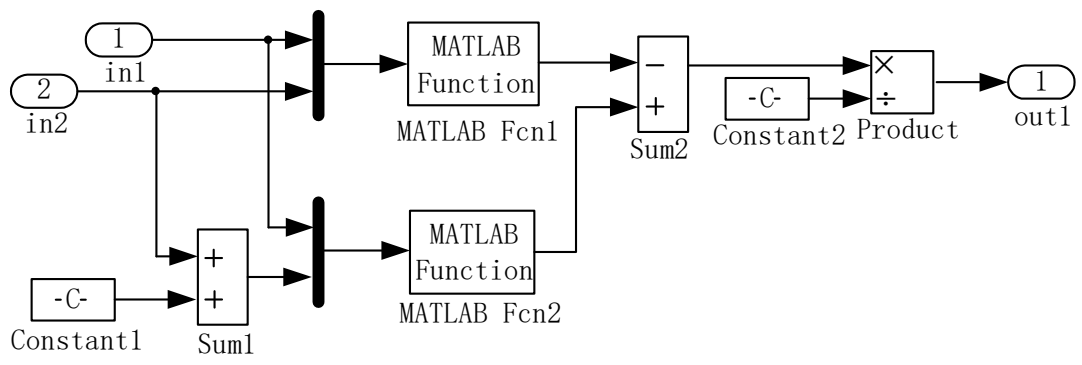

Figure 13. One phase electromagnetic torque calculation module.

In the module, "ln1" is the instantaneous current value, "in2" is the instantaneous converted relative rotor place value, and the export of module "out1" is the one phase electromagnetic torque instantaneous value. "Constant1" and "Constant 2 " are the rotor position increment, $\Delta \theta$.

The magnetic co-energy curves data of the motor in Figure 12 is stored in MATLAB Functions by data, such as "MATLAB FCn1", "MATLAB Fcn2" in Figure 13. During calculating for computing magnetic co-energy at the given rotor place and phase current, in view of the magnetic co-energy curves in MATLAB Functions the 2D specimen insert method has been adopted.

\section{Simulated and Measured Results}

The developed SRM (see Appendix A) drive prototype with the closed-cycle control speed conducted with use of the variable angle of the PWM combined control scheme with the PI algorithm is simulated by the proposed nonlinear simulation models on MATLAB-SIMULINK, and it is also tested experimentally at the same conditions. The photography of the SRM with the torque/speed meter and the load is shown in Figure 14, where the motor is on the left, the torque/speed meter is in the middle, and the load is on the right. The picture of the 4-phase asymmetric bridge power unit with the Intel 8XC196KC MCU controller (high performance member of the MCS 96 microcontroller family) is indicated in Figure 15, where on the right the power converter is shown, the Intel controller is on the 
left, and the isolation/enlargement and current/voltage protected circuit board for major switches in the power system is shown in the middle.

In the prototype, the DC voltage of the power supply is $132 \mathrm{~V}$, the frequency of the PWM semaphore is $5.0 \mathrm{kHz}$, the major switches opening and turn-off angles in the power electronics is fixed based on the rotor speed ranges included in Table 1 . The rating output torque is $0.5 \mathrm{Nm}$ and the rating rotor speed is $900 \mathrm{rpm}$.

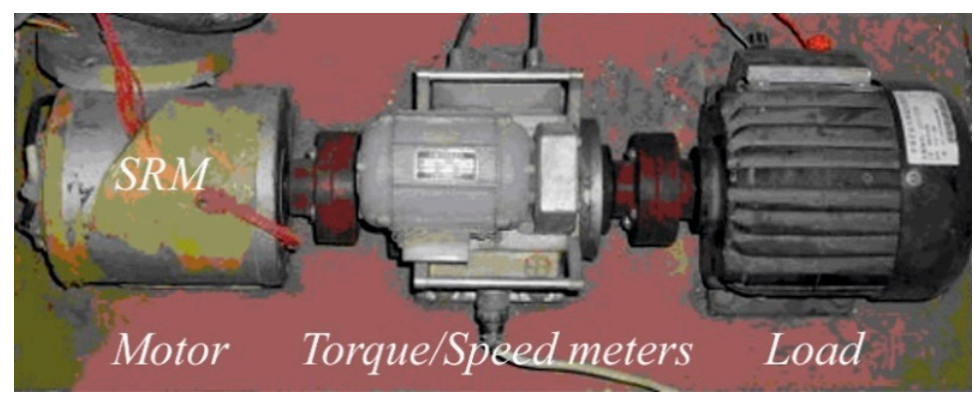

Figure 14. Measuring stand for determination of SRM-drive system properties.

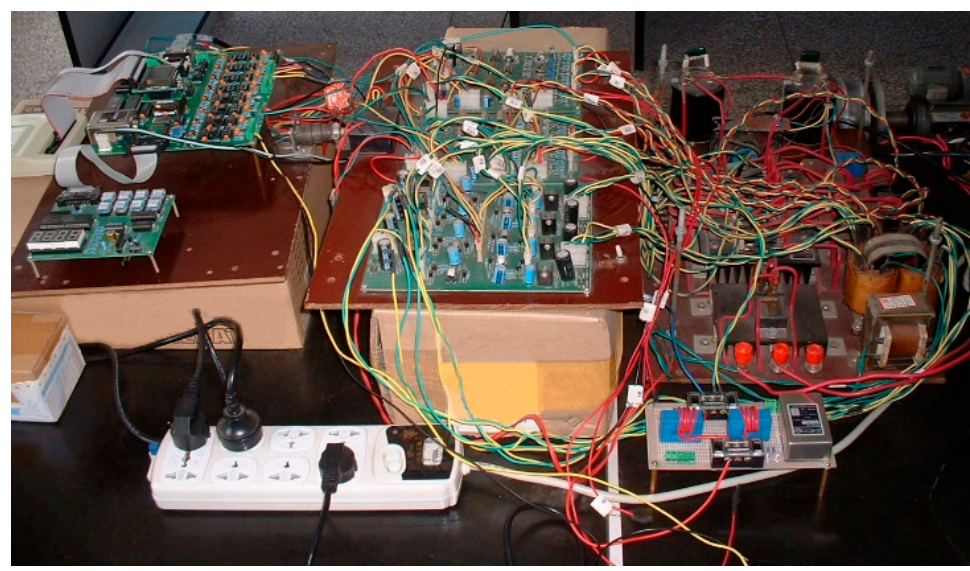

Figure 15. Power converter with the controller.

Figure 16 shows phase current waveforms obtained during simulating research and Figure 17 presents current waveforms which are result from experimental tests.

The comparison between simulated and experimental peak value of currents is given in Table 2 . As it results from this comparison, the maximum error between the calculated and measured values is not more than $8 \%$ for low speeds and not more than $6 \%$ for high speeds.

Table 2. Comparison of simulated and experimental phase current peak values.

\begin{tabular}{lcc}
\hline & Simulated (A) & Tested (A) \\
\hline $300 \mathrm{rpm}, 0.5 \mathrm{Nm}$ & 6.0 & 6.5 \\
$600 \mathrm{rpm}, 0.5 \mathrm{Nm}$ & 4.6 & 5.0 \\
$600 \mathrm{rpm}, 1.0 \mathrm{Nm}$ & 9.0 & 9.6 \\
$900 \mathrm{rpm}, 1.0 \mathrm{Nm}$ & 7.0 & 7.0 \\
\hline
\end{tabular}




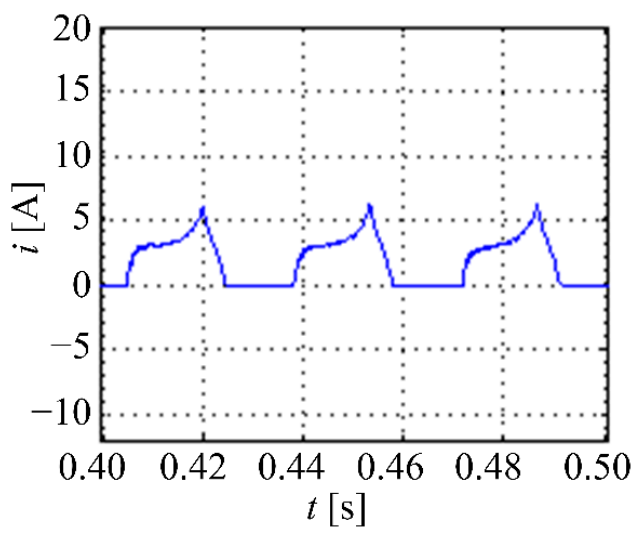

(a)

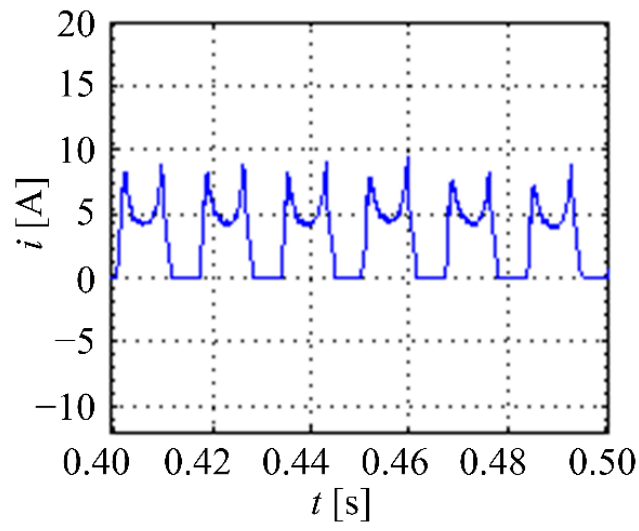

(c)

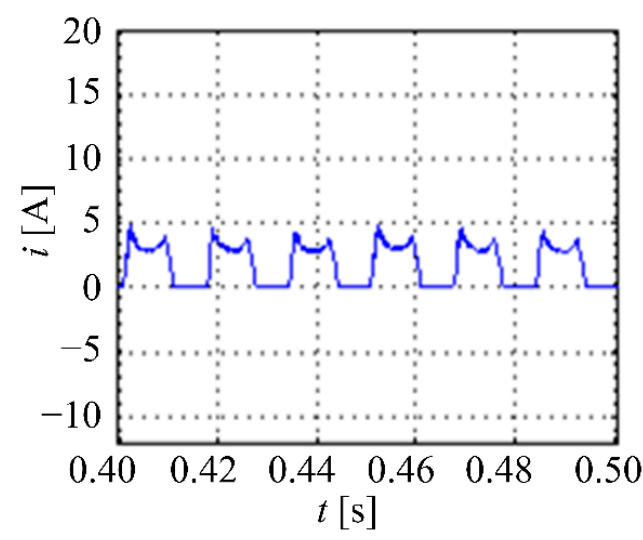

(b)

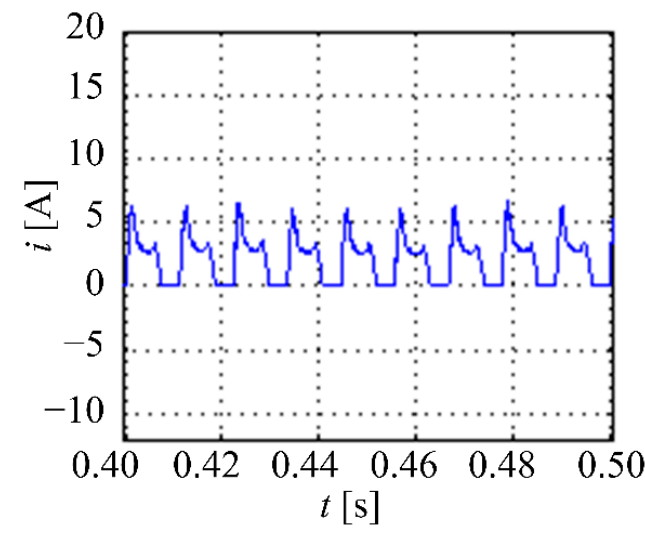

(d)

Figure 16. Phase current waveforms of the analyzed SRM machine: (a) the rotor speed is $n=300 \mathrm{rpm}$ and the load is $T=0.5 \mathrm{Nm}$; (b) $n=600 \mathrm{rpm}$ and $T=0.5 \mathrm{Nm}$; (c) $n=600 \mathrm{rpm}$ and $T=1.0 \mathrm{Nm}$; (d) $n=900 \mathrm{rpm}$ and $T=1.0 \mathrm{Nm}$.

Based on Table 1, the opening angle is fixed at $2.5^{\circ}$ in Figures $16 \mathrm{a}$ and $17 \mathrm{a}$, the opening angle is fixed at $0^{\circ}$ in Figures $16 \mathrm{~b}-\mathrm{d}$ and $17 \mathrm{~b}-\mathrm{d}$. The turn-on angle in Figures 16a and 17a are later than those in Figures 16b-d and 17b-d, so that the ascending rate of the phase current in the former case is lower than the ascending rate of the phase current in the latter. At the same rotor speed, the load in Figures 16c and 17c is larger than the load in Figures $16 \mathrm{~b}$ and $17 \mathrm{~b}$, so that the duty ratio of the PWM semaphore in Figures 16c and 17c is larger than that in Figures 16b and 17b, the phase current in Figures $16 \mathrm{c}$ and $17 \mathrm{c}$ is bigger than that in Figures $16 \mathrm{~b}$ and $17 \mathrm{~b}$.

Figures 16 and 17 prove that at the same rotor speed and load, simulated phase current waveforms agree basically with the experimental ones.

The curves of simulated rotor speeds are given in Figure 18 and the curves of experimentally tested rotor speeds are given in Figure 19. The comparison of simulated and tested rotor speeds is given in Table 3. 


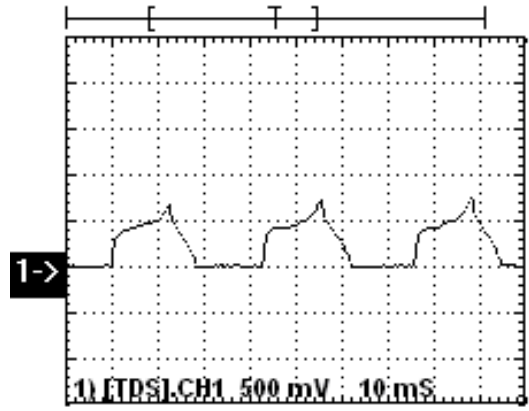

(a)

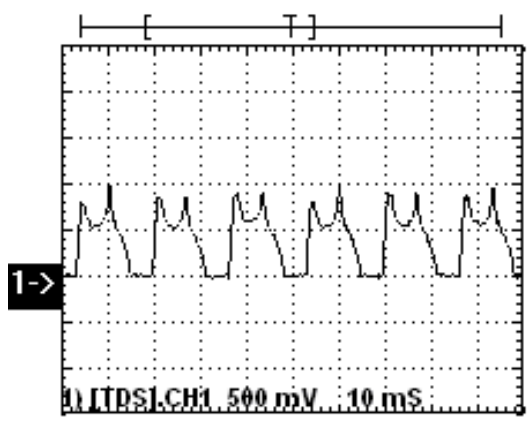

(c)

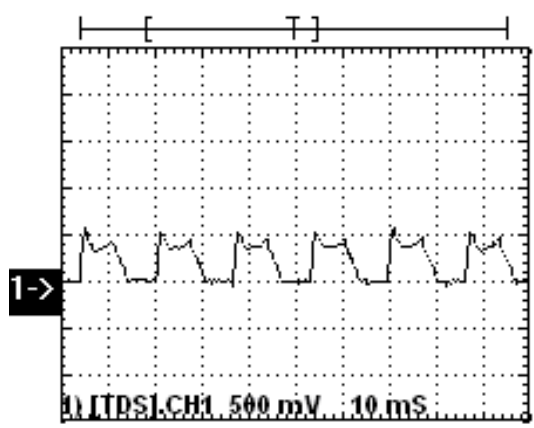

(b)

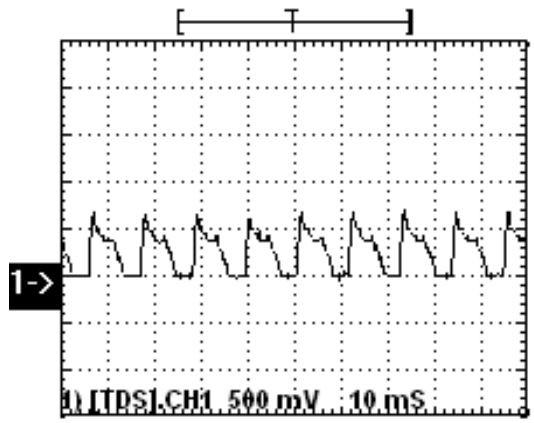

(d)

Figure 17. Tested phase current waveforms (ordinate: $5.0 \mathrm{~A} /$ div., abscissa: $10.0 \mathrm{~ms} /$ div.): (a) the rotor speed is $n=300 \mathrm{rpm}$ and the load is $T=0.5 \mathrm{Nm}$; (b) $n=600 \mathrm{rpm}$ and $T=0.5 \mathrm{Nm}$; (c) $n=600 \mathrm{rpm}$ and $T=1.0 \mathrm{Nm} ;(\mathbf{d}) n=900 \mathrm{rpm}$ and $T=1.0 \mathrm{Nm}$.

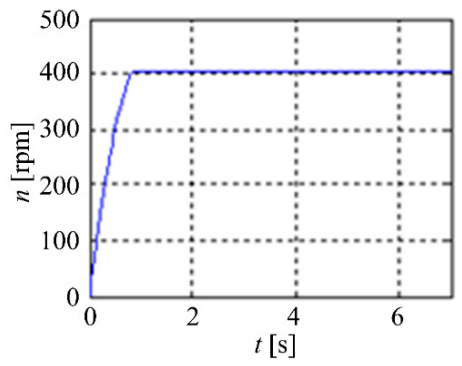

(a)

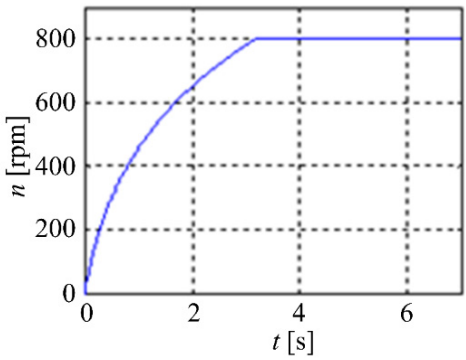

(b)

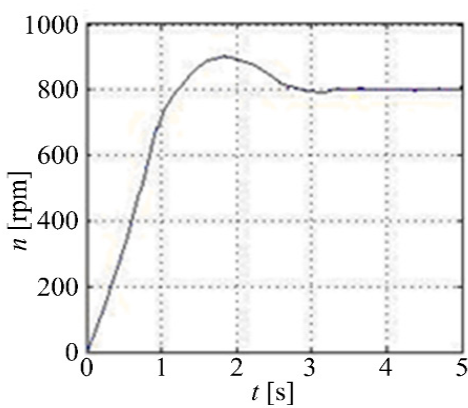

(c)

Figure 18. Simulated rotor speed curves: (a) the given rotor speed is $n=400 \mathrm{rpm}$, and the load is $T=0.05 \mathrm{Nm}$; (b) $n=800 \mathrm{rpm}$ and $T=0.05 \mathrm{Nm}$; (c) $n=800 \mathrm{rpm}$ and $T=0.50 \mathrm{Nm}$. 


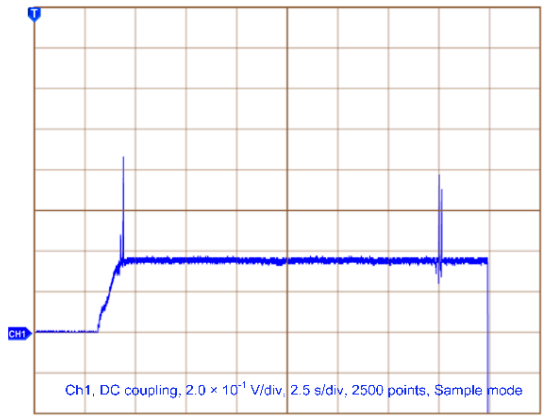

(a)

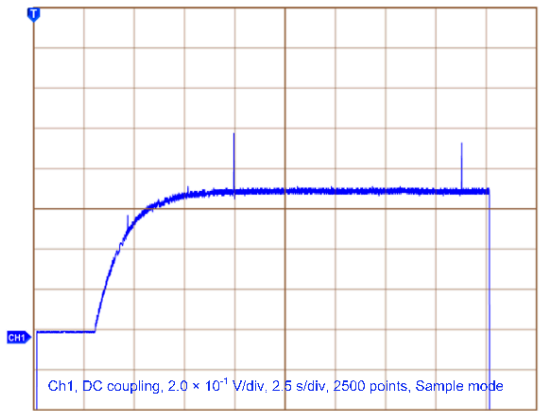

(b)

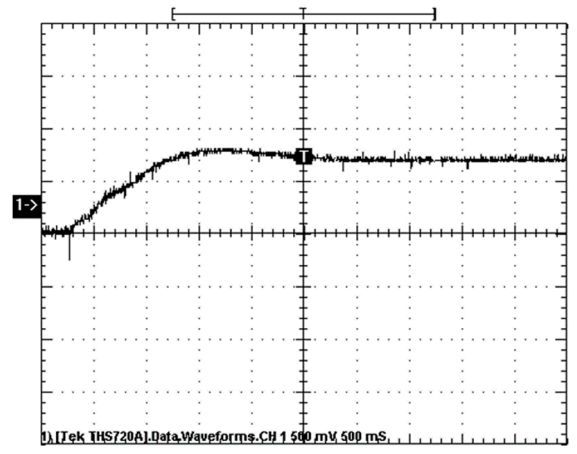

(c)

Figure 19. Curves of the tested rotor speed: (a) the given rotor speed is $n=400 \mathrm{rpm}$, and the load is $T=0.05 \mathrm{Nm}$ (ordinate: $230 \mathrm{rpm} /$ div., abscissa: $2.5 \mathrm{~s} / \mathrm{div}$.); (b) $n=800 \mathrm{r} / \mathrm{min}$ and $T=0.05 \mathrm{Nm}$ (ordinate: $230 \mathrm{rpm} /$ div., abscissa: $2.5 \mathrm{~s} /$ div.); (c) $n=800 \mathrm{r} / \mathrm{min}$ and $T=0.50 \mathrm{Nm}$ (ordinate: $570 \mathrm{rpm} /$ div., abscissa: $0.5 \mathrm{~s} /$ div.).

Table 3. Comparison simulated and tested rotor speed curves.

\begin{tabular}{|c|c|c|c|c|c|c|}
\hline & \multicolumn{2}{|c|}{$400 \mathrm{rpm}, 0.05 \mathrm{Nm}$} & \multicolumn{2}{|c|}{$800 \mathrm{rpm}, 0.05 \mathrm{Nm}$} & \multicolumn{2}{|c|}{$800 \mathrm{rpm}, 0.50 \mathrm{Nm}$} \\
\hline & Simulated & Tested & Simulated & Tested & Simulated & Tested \\
\hline Rising time (s) & 0.70 & 0.70 & 2.60 & 2.70 & 1.00 & 1.00 \\
\hline Settling time (s) & 0.80 & 0.80 & 3.10 & 3.10 & 3.30 & 3.25 \\
\hline Overshoot (\%) & 0.00 & 0.00 & 0.00 & 0.00 & +12.50 & +14.29 \\
\hline
\end{tabular}

As can be seen, the curves of the simulated rotor speeds agree with the tested experimentally ones at the same certain rotor speed and load, and the closed-cycle rotor speed control can be implemented by the PI controller which works with high accuracy. All this proves the correctness of the adopted assumptions and the good functioning of the proposed method of SRM control.

\section{Conclusions}

The presented nonlinear simulation model of the 4-phase 8/6 poles SRM drive has been developed on a MATLAB-SIMULINK platform, which is combined with the magnetization curves data computed by the 2D electromagnetic field FE analysis (Figures 11 and 12). The nonlinear electrical meshwork model of the 4-phase asymmetric bridge power electronics main circuit and the closed-cycle rotor speed control strategy have been realized by the variable angle pulse width modulation combined control scheme with the PI algorithm. It includes one main module and seven sub-modules, such as: controller, one phase simulation module, rotor place angle conversion module, power electronics module, phase current computation module, "subsystem" module and one phase electromagnetic torque computation module (Figure 4). The magnetization curves data of the motor are stored in the 
MATLAB functions, the magnetic co-energy curves data of the motor calculated from the magnetization curves data are also stored in other MATLAB functions. The two dimensions specimen insert method was adopted in MATLAB functions for computing the flux linkage and the magnetic co-energy curves at the given rotor position and the given phase current. The waveforms of the simulated current agree very well with the waveforms of the experimentally tested ones at the same rotor speed and load (Figures 16 and 17). The simulated rotor speed curves also agree basically with the curves of the experimentally tested rotor speeds (Figures 18 and 19). It was proved that the method of the proposed nonlinear simulation models of the analyzed SRM drive is correct, and the final model is accurate. The main achievement of the work is the creation of a full stable algorithm for controlling SRM machines. The limitations of the proposed algorithm are caused by the accuracy of the SR machine FEM model and the quality of the determined torque and magnetic flux values. On the hardware side, the limitations are the speed and accuracy of the hardware used. The results obtained in this paper enable better control of SR machines in different working states. The proposed method can be applied to develop other simulation models of SRM drives with other double salient reluctance motors and different topologies of the control system and power electronics. Simulation models proposed in the paper can contribute to develop semi-physical simulation platforms which can be used for actual time simulation and-as a consequence-facilitate development of the SRM drive. In the future, research will consist in improving the proposed method and automating the connection of individual computational programs: FEM, MATLAB and SIMULINK.

Author Contributions: Conceptualization, X.W., R.P. and M.W.; methodology, R.P. and M.W.; software, X.W.; validation, X.W., R.P. and M.W.; formal analysis, R.P. and M.W.; data processing, X.W.; writing-original draft preparation, X.W.; writing - review and editing, R.P. and M.W. All authors have read and agreed to the published version of the manuscript.

Funding: This research was funded by Xuzhou Science and Technology Plan Project, grant number KH17004.

Conflicts of Interest: The authors declare no conflict of interest.

\section{Appendix A}

Table A1. Parameters of tested Switch Reluctance Machine.

\begin{tabular}{cc}
\hline \multicolumn{2}{c}{ SRM Parameters } \\
\hline Phase number & 4 \\
Number of stator pole & 8 \\
Number of rotor pole & 6 \\
Stator bore diameter & $78.0 \mathrm{~mm}$ \\
Stator outer diameter & $130.0 \mathrm{~mm}$ \\
Air gap length & $0.15 \mathrm{~mm}$ \\
Rotor bore diameter & $30.0 \mathrm{~mm}$ \\
Length of laminated iron core & $135 \mathrm{~mm}$ \\
Number of turns per pole & 7 \\
Type of iron & DR510-50 \\
\hline
\end{tabular}

\section{References}

1. Miller, T.J.E. Switched Reluctance Motors and Their Control; Oxford University Press: Oxford, UK, 1993.

2. Chen, H.; Gu, J.J. Implementation of three-phase switched reluctance machine system for motors and generator. IEEE/ASME Trans. Mechatron. 2010, 15, 421-432. [CrossRef]

3. Radimov, N.B.; Rabinovici, R. Switched reluctance machines as three-phase ac autonomous generator. IEEE Trans. Magn. 2006, 42, 3760-3764. [CrossRef]

4. Calverley, S.D.; Jewell, G.W.; Saunders, R.J. Aerodynamic losses in switched reluctance machine. IEEE Proc. Electr. Power Appl. 2000, 147, 443-448. [CrossRef]

5. Krishnan, R.; Blanding, D. High reliability SRM driver system for aerospace application. Proc. IEEE APEC 2003, 2, 1110-1115. 
6. Chang, Y.; Liaw, C. On the design of power circuit and control scheme for switched reluctance generator. IEEE Trans. Power Electron. 2008, 23, 445-454.

7. Echenique, E.; Dixon, J.; Cárdenas, R.; Peña, R. Sensorless control for a switched reluctance wind generator, based on current slopes and neural networks. IEEE Trans. Ind. Electron. 2009, 56, 817-825. [CrossRef]

8. May, H.; Canders, W.-R.; Palka, R.; Holub, M. Optimisation of the feeding of switched reluctance machines for high speed and high power applications. Stud. Appl. Electromagn. Mech. 2002, 22, 489-494.

9. Yan, W.; Chen, H.; Liu, X.; Ma, X.; Lv, Z.; Wang, X.; Palka, R.; Chen, L.; Wang, K. Design and multi-objective optimisation of switched reluctance machine with iron loss. IET Electr. Power Appl. 2019, 13, 435-444. [CrossRef]

10. Holub, M.; Palka, R.; Canders, W.-R. Control of Switched Reluctance Machines for Flywheel Energy Storage Applications. Electromotion 2005, 12, 185-191.

11. Nie, R.; Chen, H.; Liu, J.; Zhao, W.; Wang, X.; Palka, R. Compensation analysis of longitudinal end effect in three-phase switched reluctance linear machines. ET Electr. Power Appl. 2020, 14, 165-174. [CrossRef]

12. Krishnamurthy, M.; Edrington, C.S.; Emadi, A.; Asadi, P.; Ehsani, M.; Fahimi, B. Making the Case for Applications of Switched Reluctance Motor Technology in Automotive Products. IEEE Trans. Power Electron. 2006, 21, 659-675. [CrossRef]

13. Gulez, K.; Adam, A.A.; Pastaci, H. A novel direct torque control algorithm for ipmsm with minimum harmonics and Torque Ripples. IEEE/ASME Trans. Mechatron. 2007, 12, 223-227. [CrossRef]

14. Monmasson, E.; Idkhajine, L.; Cirstea, M.N.; Bahri, I.; Tisan, A.; Naouar, M.W. FPGAs in industrial control applications. IEEE Trans. Ind. Informat. 2011, 7, 224-243. [CrossRef]

15. Orlowska-Kowalska, T.; Kaminski, M. FPGA implementation of the multilayer neural network for the speed estimation of the two-mass drive system. IEEE Trans. Ind. Informat. 2011, 7, 436-445. [CrossRef]

16. Bertoluzzo, M.; Buja, G. Development of electric propulsion systems for light electric vehicles. IEEE Trans. Ind. Informat. 2011, 7, 428-435.

17. Orlowska-Kowalska, T.; Szabat, K. Damping of torsional vibrations in two-mass system using adaptive sliding neuro-fuzzy approach. IEEE Trans. Ind. Informat. 2008, 4, 47-57. [CrossRef]

18. Lai, C.; Hsu, P. Design the remote control system with the time-delay estimator and the adaptive smith predictor. IEEE Trans. Ind. Informat. 2010, 6, 73-80.

19. Polic, A.; Jezernik, K. Closed-loop matrix based model of discrete event systems for machine logic control design. IEEE Trans. Ind. Informat. 2005, 1, 39-46.

20. Filev, D.P.; Chinnam, R.B.; Tseng, F.; Baruah, P. An industrial strength novelty detection framework for autonomous equipment monitoring and diagnostics. IEEE Trans. Ind. Informat. 2010, 6, 767-779. [CrossRef]

21. Kong, K.; Bae, J.; Tomizuka, M. Control of rotary series elastic actuator for ideal force-mode actuation in human-robot interaction applications. IEEE/ASME Trans. Mechatron. 2009, 14, 105-118. [CrossRef]

22. Lu, L.; Chen, Z.; Yao, B.; Wang, Q. Desired compensation adaptive robust control of a linear-motor-driven precision industrial gantry with improved cogging force compensation. IEEE/ASME Trans. Mechatron. 2008, 13, 617-624. [CrossRef]

23. Liu, H.; Meusel, P.; Hirzinger, G.; Jin, M.; Liu, Y.; Xie, Z. The modular multisensory DLR-HIT-hand: Hardware and software architecture. IEEE/ASME Trans. Mechatron. 2008, 13, 461-469.

24. Michon, M.; Calverley, S.D.; Powell, D.J.; Clark, R.E.; Howe, D. Dynamic model of a switched reluctance machine for use in a saber based vehicular system simulation. In Proceedings of the IEEE 40th IAS Annul Meeting, Hong Kong, China, 2-6 October 2005; pp. 2280-2287.

25. Farshad, M.; Faiz, J.; Lucas, C. Development of analytical models of switched reluctance motor in two-phase excitation mode: Extended miller model. IEEE Trans. Magn. 2005, 41, 2145-2155. [CrossRef]

26. Charton, J.T.; Corda, J.; Stephenson, J.M.; Randall, S.P. Dynamic modelling of switched reluctance machines with iron losses and phase interactions. IEEE Proc.-Electr. Power Appl. 2006, 153, 327-336. [CrossRef]

27. Jain, A.K.; Mohan, N. Dynamic modeling, experimental characterization, and verification for SRM operation with simultaneous two-phase excitation. IEEE Trans. Ind. Electron. 2006, 53, 1238-1249. [CrossRef]

28. Ding, W.; Liang, D. Modeling of a 6/4 switched reluctance motor using adaptive neural fuzzy inference system. IEEE Trans. Magn. 2008, 44, 1796-1804. [CrossRef]

29. Husain, I.; Hossain, S.A. Modeling, simulation, and control of switched reluctance motor drives. IEEE Trans. Ind. Electron. 2005, 52, 1625-1634. [CrossRef] 
30. Khalil, A.; Husain, I. A Fourier series generalized geometry-based analytical model of switched reluctance machines. IEEE Trans. Ind. Appl. 2007, 43, 673-684.

31. Loop, B.; Essah, N.; Sudhoff, S. A basis function approach to the nonlinear average value modeling of switched reluctance machines. IEEE Trans. Energy Convers. 2006, 21, 60-68. [CrossRef]

32. Vujicic, V.P. Modeling of a switched reluctance machine based on the invertible torque function. IEEE Trans. Magn. 2008, 44, 2186-2194. [CrossRef]

33. Xia, C.; Shi, T.; Xue, M. A new rapid nonlinear simulation method for switched reluctance motors. IEEE Trans. Energy Convers. 2009, 24, 578-586. [CrossRef]

34. Burkhart, B.; Klein-Hessling, A.; Ralev, I.; Weiss, C.P.; De Doncker, R.W. Technology, Research and Applications of Switched Reluctance Drives. CPSS Trans. Power Electron. Appl. 2017, 2, 12-27. [CrossRef]

35. Sovicka, P.; Rafajdus, P.; Vavrus, V. Switched reluctance motor drive with low-speed performance improvement. Electr. Eng. 2020, 102, 27-41. [CrossRef]

36. Caramia, R.; Piotuch, R.; Palka, R. Multiobjective FEM optimization of BLDC motor based on Matlab and Maxwell scripting capabilities. Arch. Electr. Eng. 2014, 63, 115-124. [CrossRef]

37. Palka, R.; Piotuch, R. Usage of FEM for synthesis of dead-beat current controller for permanent magnet synchronous motor. COMPEL Int. J. Comput. Math. Electr. Electron. Eng. 2019, 38, 1386-1400. [CrossRef]

Publisher's Note: MDPI stays neutral with regard to jurisdictional claims in published maps and institutional affiliations.

(C) 2020 by the authors. Licensee MDPI, Basel, Switzerland. This article is an open access article distributed under the terms and conditions of the Creative Commons Attribution (CC BY) license (http://creativecommons.org/licenses/by/4.0/). 